\title{
Headaches in civil servants: effect on work and leisure
}

\author{
M L E ESPIR, ${ }^{1}$ J THOMASON, ${ }^{1}$ JN BLAU,${ }^{2}$ ZARRINA KURTZ ${ }^{3}$ \\ From the Civil Service Occupational Health Service, ${ }^{1}$ London, National Hospital for Nervous Diseases ${ }^{2}$ and \\ Institute of Child Health, ${ }^{3}$ London, UK
}

ABSTRACT Headaches in a group of civil servants and their effects on work and leisure activities, the medication taken, and numbers consulting their general practitioners during a year were assessed by a self administered questionnaire sent to 1000 civil servants in sections of a government department in London. The response rate was $74.7 \%$. Altogether $77 \%$ of the respondents reported having had headaches in the previous 12 months. There was a higher prevalence in women (88\%) than men $(70 \%)$ and a significant decrease with increasing age. Women also had more frequent and severe headaches than men: $34 \%$ reported that headaches had interfered with work, either by impaired performance, making them leave work early, or by stopping them coming into work. About half of those who reported having severe headaches denied that they had affected their work, indicating difficulty in interpreting the term "severe." Nevertheless, $22 \%$ said that headaches interfered with their leisure activities as well as work which may be regarded as further evidence that the condition was truly disabling. Eighty per cent of those with headaches took medication, but within the past year only $11 \%$ had consulted their general practitioner and only $2 \cdot 2 \%$ had been referred for further specialist opinion. Of the $22 \%$ who had not had a headache during the previous 12 months, $5.6 \%$ had never had a headache. In this group there was a larger proportion of men, a higher proportion with increasing age, and a higher proportion in non-desk working grades. Differentiation of the causes of headaches was not attempted in this survey but it is concluded that the extent to which they interfere with work and leisure is an important guide to their severity. It is suggested that the occupational health services may have an important role in assessing the causes of headaches and instituting preventive measures that benefit both the worker and industry.

Headache is a frequent presenting symptom in general practice, occurring either alone or in association with other symptoms. ${ }^{12}$ Tension headaches and migraine usually top the list of causes, although they become proportionally less in people over 50 , surveys showing a wide range of prevalence varying with the definitions used and population selected. ${ }^{34}$ Self medication by headache sufferers has generally been found to be common and many do not seek medical advice. ${ }^{s-7}$ The severity of headaches is notoriously difficult to assess, partly because they are subjective and terms used to describe severity depend on the individual's interpretation. At work, headaches tend to be treated dismissively by colleagues and line managers and regarded as having little importance. That they may be disabling and interfere with work is not always appreciated. ${ }^{8}$ Furthermore, there is little information on the extent to which headaches affect leisure or on

Accepted 11 May 1987 the proportion of people who have never experienced headache in their life or so rarely as to be of no importance. In this study we have attempted to assess these aspects in a population of civil servants, using the term "headache" in its generic sense to include all types.

\section{Methods}

A questionnaire was devised, modified from Waters, ${ }^{9}$ and was evaluated in a pilot study of 84 civil servants working in a single section of a government department in London. As a result of the findings, further changes were made to the questionnaire which was then sent in March 1984 to 1044 civil servants, the entire staff of all grades working in a group of London offices of the same government department, excluding the section that had participated in the pilot study. None of the buildings had air conditioning. Basic data on age, sex, grade, and duration of employment in the Civil Service were provided by the chief welfare officer 
Table 1 Age, sex, grade, and duration of employment in the Civil Service of 1000 staff comprising the population surveyed

\begin{tabular}{|c|c|c|c|}
\hline Age (y'ears) & Men & Women & Total \\
\hline $\begin{array}{l}18-19 \\
20-34 \\
35-49 \\
\geqslant 50\end{array}$ & $\begin{array}{r}3 \\
159 \\
135 \\
215 \\
512\end{array}$ & $\begin{array}{r}6 \\
174 \\
110 \\
198 \\
488\end{array}$ & $\begin{array}{r}9 \\
333 \\
245 \\
413 \\
1000\end{array}$ \\
\hline \multicolumn{4}{|l|}{ Grades } \\
\hline $\begin{array}{l}\text { Senior management } \\
\text { (principals to under } \\
\text { secretary) and legal } \\
\text { professionals }\end{array}$ & 46 & 19 & 65 \\
\hline Executives & 234 & 149 & 383 \\
\hline $\begin{array}{l}\text { Clerical grades, secretaries, } \\
\text { typists, data processors }\end{array}$ & 116 & 207 & 323 \\
\hline $\begin{array}{l}\text { Messengers, paperkeepers, } \\
\text { office keepers, ushers, } \\
\text { security officers }\end{array}$ & 110 & 113 & 223 \\
\hline Others & $\begin{array}{r}6 \\
512\end{array}$ & $\begin{array}{r}0 \\
488\end{array}$ & $\begin{array}{r}6 \\
1000\end{array}$ \\
\hline $\begin{array}{l}\text { Duration of service (years) } \\
<1 \\
1-2 \\
3-5 \\
6-10 \\
\geqslant 10\end{array}$ & $\begin{array}{c}\text { Total } \\
23 \\
65 \\
137 \\
301 \\
474 \\
1000\end{array}$ & & \\
\hline
\end{tabular}

from computerised staff records, confidentiality having been assured. Of the original 1044, 44 had to be excluded as their questionnaires could not be delivered because of transfers, retirements, or resignations after the register had been compiled. Table 1 shows the demographic data of the 1000 civil servants surveyed. They are representative of the Civil Service as a whole, except in the clerical grades where the study sample had a higher proportion of men ( $51 \%$ ) than in the Civil Service as a whole $(32 \%)$. Ninety five per cent worked full time.

After six weeks about 600 had replied. Reminders were sent out to the remaining 400 , bringing the total number of questionnaires returned to 755 of whom eight indicated refusal to participate.

The questionnaire was designed to obtain information on whether or not headaches had occurred in the past 12 months, their frequency, duration, severity, and associated symptoms. In addition, all staff were asked whether headaches had interfered $(a)$ with their work - that is, performance of work, made them leave work early, or stopped them coming into work, $(b)$ with their leisure or social activities, and $(c)$ about the medical treatment and advice obtained.

\section{Results}

Overall, 747 of the total sample returned completed the questionnaires. No significant differences between responders and non-responders were found in respect of age, sex, grade, or duration of service, or whether working full or part time.

(Results are presented with emphasis on those reaching statistical significance at the $5 \%$ level. Not all responders answered all the questions, accounting for some minor discrepancies.)

HEADACHE IN THE PAST 12 MONTHS

Of the 747 responders, $578(77 \%)$ reported having at least one headache in the past 12 months. There was a significant difference in the occurrence of headaches reported by men $(70 \%)$ compared with women $(88 \%)$. The proportion of those with headaches during the past 12 months showed a significant decrease with increasing age; $89 \%$ of those aged $20-34,80 \%$ aged $35-49$, and $69 \%$ aged $50-64$.

A significantly larger proportion of executives, and clerical, secretarial, typing, and data processing grades of staff $(81.5 \%)$ reported headaches in the past 12 months compared with messengers, paperkeepers, office keepers, and ushers $(62 \cdot 6 \%)$.

\section{FREQUENCY}

A frequency of less than one headache a month was reported by most $(55.6 \%)$ of those who had had headaches in the past 12 months; one to three a month by $33.7 \%$; and one or more a week by $10 \cdot 6 \%$. Those with the highest frequency were most likely to be women, particularly in the secretarial and typing grades.

\section{DURATION}

Although $71 \%$ reported headaches lasting between one and 24 hours, $12 \%$ reported that their headaches lasted more than one day. Headaches lasting one hour or less were reported by $17 \%$; these included a few people who reported headaches lasting for only a few seconds.

\section{SEVERITY}

A total of $394(69 \%)$ reported having severe or moderate headaches, although some added that they also had mild headaches; 179 (31\%) had mild headaches only; five did not answer this question. A higher proportion of women (particularly secretaries, typists, and ushers) than men had severe or moderate headaches $(78 \%: 57 \%)$. In senior management (these grades being predominantly male) the proportion with mild headaches was the same as those with severe or moderate. The same proportion of full timers and part timers had severe or moderate headaches. The severity of the headache was unrelated to duration of service.

\section{ASSOCIATED SYMPTOMS}

Table 2 shows that $224(39 \%)$ reported having other symptoms associated with their headaches. 
Table 2 Associated symptoms reported (either singly or in combination) by those who had had headaches and the numbers affected

Nausea, vomiting, anorexia

Vision affected

Sensitivity to bright light or noise

Needed quiet, dark, to lie down

Felt drowsy or tired

Felt tense, irritable, ill, depressed, withdrawn

Needed to avoid bending or sudden movement

45
16
11
92
31
56
10

Table 3 Effect of headache on work; numbers reporting that headaches affected their performance at work, made them leave work early, or stopped them coming into work (either singly or in combination

Performance affected (PA) only

Left work early (LWE) only

Stopped coming to work (SCW) only

PA and LWE

PA and SCW

LWE and SCW

PA and LWE and SCW

$\begin{array}{r}83 \\ 7 \\ 18 \\ 26 \\ 37 \\ 2 \\ 24 \\ 197 \\ \hline\end{array}$

EFFECT OF HEADACHE ON WORK

Of the 578 who had had headaches in the past 12 months, $197(34 \%)$ said that headaches had interfered with their work, either by impairing their performance, making them leave work early, or preventing them coming into work. Table 3 shows the numbers whose work was affected in one or more of these ways: $170(29 \%)$ reported that headaches during the past 12 months had impaired their work performance but in most this occurred less than once a month. Headaches made $59(10 \%)$ of them leave work early, between one and six times a year. Headaches stopped $81(14 \%)$ of them coming into work; 74 lost one to five days a year and the remaining seven lost between one and three weeks.

Although $381(66 \%)$ said their headaches had not affected their work in any of these aspects, 217 reported that the headaches were severe or moderate.

\section{EFFECT OF HEADACHE ON LEISURE, SOCIAL, OR} DOMESTIC ACTIVITIES

Of the 578 who had had headaches during the past 12 months, $173(30 \%)$ reported that they had interfered with their leisure, social, or domestic activities, which included 23 whose headaches were only mild. The activities affected, singly or in combination, are listed in table 4.

In 47 leisure but not work was affected, in 126 both leisure and work were affected, and in 75 work but not leisure was affected. The remaining 330 with headaches reported that neither work nor leisure was affected.
Table 4 Leisure, social, or domestic activities affected (either singly or in combination) in those who had had headaches and the numbers affected

Everything, most things, routine
Thinking clearly, concentrating
Reading, writing
Watching TV/films
Entertaining, socialising, going out
Strenuous activity, sport
Housework, cooking
Driving
Other activities

\section{MEDICATION TAKEN}

Of the 578 who had had headaches during the past 12 months, 460 reported taking "medication," some more than one preparation (table 5).

\section{Table 5 "Medication" taken by those who had had headaches and the numbers affected. (Some took more than one of those listed)}

Analgesics

Antiemetics

Specific antimigraine drugs

Tranquillisers or antidepressants

Other remedies (tea, alcohol, vitamins, etc)

Unidentifiable drugs

438
17
7
4
41
1

All those who took antiemetic and antimigraine drugs took analgesics as well. Of the 438 who had taken analgesics, with or without antiemetic or antimigraine drugs, $314(71.7 \%)$ reported having severe or moderate headaches, whereas of the 140 not taking these drugs, only $80(57 \cdot 1 \%)$ had severe or moderate headaches.

Of the 394 with severe or moderate headaches, $79.7 \%$ were taking analgesics, with or without antiemetic or antimigraine drugs; $20.3 \%$ took no medication. Of the 179 with mild headaches only, $69.3 \%$ were taking analgesics, with or without antiemetic or antimigraine drugs; $30.7 \%$ took no drugs. Of the 118 who denied taking any medication, 60 reported that their headaches were severe or moderate.

\section{CONSULTATIONS WITH ORTHODOX MEDICAL OR OTHER PRACTITIONERS}

Of the 578 with headaches in the past 12 months, only $62(11 \%)$ had consulted their general practitioner, of whom 56 had severe or moderate headaches and 28 had taken one or more days off work. Five hundred and nine $(88 \%)$ had not consulted their general practitioner. A significantly higher proportion of the 62 who had consulted their general practitioner than of the 509 who did not had taken time off work. (Seven did not answer this question.)

During the past 12 months, 13 people had sought help from various medical and other specialists, five of whom were practising complementary medicine. 
Table 6 Comparison of male:female ratio of those who had had headaches in the past 12 months and those who had not

\begin{tabular}{llrl}
\hline & Men & Women & Total \\
\hline Headaches & $260(45 \%)$ & $318(55 \%)$ & 578 \\
No headaches & $110(71 \%)$ & $45(29 \%)$ & 155 \\
\hline
\end{tabular}

NO HEADACHE IN THE PAST YEAR

Of the 162 who said that they had not had a headache in the past 12 months, 113 reported that they had had headaches previously and 42 that they had never had a headache. Seven did not reply to this part of the question and have been excluded from further analysis of this group.

Table 6 shows that of the 155 who gave adequate information and who had not had a headache in the past 12 months, the male:female ratio was $71 \%: 29 \%$, very different from the 578 who had headaches in the past year; male:female ratio $45 \%: 55 \%$.

There was no significant sex difference between those who had not had a headache in the past 12 months but had done so previously and those who had never had a headache.

Table 7 shows that of the 370 men whose replies could be analysed, $30 \%$ had had no headache in the past year, whereas of the 363 women, only $12 \%$ had not had a headache in the past year.

\section{NEVER HAD A HEADACHE}

Further analysis of the $42(5.6 \%$ of the respondents) who stated that they had never had a headache showed a larger proportion of men, a higher proportion with increasing age, and a higher proportion in non-desk working grades - for example, messengers and ushers. These same trends were found in the 113 who had not had headaches in the past year but had done so previously. There was no consistent relationship with duration of service; of the $\mathbf{4 2}$ who had never had a headache, 24 had 10 years service or more and 18 less than 10 years service.

\section{Discussion}

The response rates of previous surveys of headache and migraine in diverse groups of people have varied from $35.9 \%$ to $90 \%$ and over. ${ }^{10}$ " Our response rate of $74 \cdot 7 \%$ is comparable with others using a postal self

Table 7 Comparison of those who had had headaches in the past 12 months and those who had not according to sex

\begin{tabular}{lccc}
\hline & Headaches & No headaches & Total \\
\hline Men & $260(70 \%)$ & $110(30 \%)$ & 370 \\
Women & $318(88 \%)$ & $45(12 \%)$ & 363 \\
\hline
\end{tabular}

administered questionnaire without personal contact between subjects and any member of the research team. ${ }^{12}$

In our population of civil servants ranging from senior management to all other grades the proportion of those who said they had experienced headaches during the past 12 months $(77 \%)$ is comparable with that found in other studies. ${ }^{3}$ Similarly, the higher prevalence of headaches in women and the decrease with increasing age have been observed previously. Our finding that sedentary workers (secretaries, typists, as well as executives) had more headaches than those who moved around (ushers and messengers) is of interest. This was unrelated to sex differences and is not likely to be due to a different socioeconomic status among the different grades as this has not influenced the prevalence of headaches in previous population studies. Although stress or postural problems could be relevant, if sedentary work is also a significant factor then occupational health services may be able to help by advising exercise during break periods. Work related headache may also occur as a symptom of "building sickness," as occurred in $31 \%$ of those working in an air conditioned building and $15 \%$ of those in a naturally ventilated building. ${ }^{13}$ Many causes have been postulated but current evidence suggests that they are probably related to factors other than the ventilation system.

A large multioccupation study carried out in 1975-6 by Green showed that $67 \%$ of those with migraine were absent from work for one day or more in a year, representing $15.8 \%$ of the total population surveyed. ${ }^{14}$ Our study has shown that headache results not only in work loss but can also interfere with efficiency, thus affecting work in $26 \%$ of the staff who respondedthat is, $34 \%$ of those who had headaches: $8 \cdot 1 \%$ lost more than a day's work in the year as a result of headaches. Although the time lost may not be large, impaired efficiency and even one day's absence of a key worker can disrupt departmental work, and if the results of our and Green's studies are applicable to industry as a whole the nation's loss would be considerable.

The effect of headaches on leisure, so far as we know, has not been studied previously. Our study has shown that in $30 \%$ of those who had headaches, they interfered with leisure, social, or domestic activities. This is a further measure of the impact that headache can have on life. We consider it important that in $22 \%$ of those who had headaches both leisure and work were affected.

Despite work being affected in $34 \%$ of those with headaches only $11 \%$ had consulted their general practitioner during the previous 12 months. Although more may have done so before this, if our findings apply also to other groups of workers then there is 
clearly a need for closer supervision by family practitioner and occupational health services to identify the conditions which may be prevented and treated effectively.

It is noteworthy that in $57 \%$ of those reporting severe headaches, work was not affected, in keeping with the clinical observation that the lay and medical uses of the term severe are not necessarily the same. Our study thus confirms that the individual's subjective assessment of severity of headache is difficult to interpret and needs careful evaluation by its effect on work, leisure, and tablet consumption.

No attempt was made in this study to diagnose the type of headache or to distinguish between those whose primary symptom was headache from those in whom it was secondary to another condition, such as influenza or sinusitis. Further thought needs to be given to the wording of questionnaires so that respondents are given guidance about the meaning of the terms headache and severe. In this study $18 \mathrm{com}$ mented that they were unsure whether they should include or exclude headaches which they attributed to other conditions or environmental factors; others may have had similar difficulty. In a prevalence survey reported recently from China respondents were screened on the basis of two questions to determine if they had ever suffered from severe headaches: (1) "Have you had a severe or very severe headache that is not related to any other illness or toothache?" and (2) "During the period of severe headache, did you decrease your activity by at least $50 \%$ ?"15 We believe that by asking about the extent to which headaches have interfered with leisure and social activities as well as with work we have a better measure of their severity and an indication whether the condition is truly disabling.

Although some of our respondents reported features suggestive of migraine-for example, an aura, vomiting, and lying in a darkened room until the headache cleared - only seven said they had taken specific antimigraine drugs. In any case we thought that we could not rely on a questionnaire or computer without a clinical interview to make a correct diagnosis, particularly as patients not infrequently have more than one type of headache, ${ }^{16}$ and the diagnosis can be difficult even when the patient is sitting before the clinician.

This study has confirmed that headaches can not only cause time lost from work but also impair performance while at work, at least subjectively. Consideration should be given to providing simple treatment for headache occurring at work as suggested by Jones and Harrop. ${ }^{17}$ This study also shows that self medication for headaches is common. Although this might be satisfactory, it could mean that the individual is not taking advantage of advances in medical knowledge and that work related factors known to the occupational health services need attention. Furthermore, relatively few of those with headaches have sought medical advice, suggesting that occupational physicians and nurses, who have the advantage of knowing about the work loss as well as the working environment, may also have an important role in assessing the causes of headaches and instituting preventive measures that benefit both the worker and industry.

We wish to thank all the respondents for taking the time and trouble to complete the questionnaire. We also thank the chief welfare officer of the government department that participated in this study for his invaluable help.

Requests for reprints to: Dr Michael Espir, 39 Hyde Park Gardens Mews, London W2 2NX.

\section{References}

1 Jerrett WA. Headaches in general practice. The Practitioner 1979:222:549-55.

2 Waters WE. Headache. London \& Sydney: Croom Helm. 1986.

3 Waters WE. Epidemiology of migraine. In: Pearce J, ed. Modern topics in migraine. London: Heinemann Medical, 1975:8-21.

4 Newland RA, Illis LS, Robinson PK, et al. A survey of headache in an English city. In: Granger ME, ed. Epidemiology and non-drug treatment of head pain: research and clinical studies in headache. Basel: Karger, 1978:1-20.

5 Waters WE. Migraine. In: Rose FC, ed. Clinical neuroepidemiology. London: Pitman Medical, 1980:384-90.

6 Nikiforow R. Headache medication habits in Northern Finland. Headache 1980;20:274-8.

7 Post D, Gubbels JW. Headache: an epidemiological survey in a Dutch rural practice. Headache 1986;26:122-5.

8 Nikiforow R, Hokkanen E. Effects of headache on working ability: a study of an urban and a rural population in Northern Finland. Headache 1979;19:214-8.

9 Waters WE, ed. The epidemiology of migraine. Bracknell: Boehringer Ingelheim, 1974:77-81.

10 Gammie KM, Waters WE. Headache and migraine in a biscuit factory. In: Waters WE, ed. Epidemiology of migraine. Bracknell: Boehringer Ingelheim, 1974:44-8.

11 Clarke GJR, Waters WE. Headache and migraine in a London general practice. In: Waters WE, ed. Epidemiology of migraine. Bracknell: Boehringer Ingelheim, 1974:14-22.

12 Nikiforow R, Hokkanen E. An epidemiological study of headache in an urban and rural population in Northern Finland. Headache 1978;18:137-45.

13 Robertson AS, Burge PS, Hedge A, et al. Comparison of health problems related to work and environmental measurements in two office buildings with different ventilation systems. $\mathrm{Br} \mathrm{Med} \mathrm{J}$ 1985;291:373-6.

14 Green JE. A survey of migraine in England 1975-1976. Headache 1977;17:67-8.

15 Cheng X-m, Ziegler DK, Li S-c, et al. A prevalence survey of "incapacitating headache" in the People's Republic of China. Neurology 1986;36:831-4.

16 Friedman AP. The epidemiology of migraine. Hemicrania 1976;7:2-4.

17 Jones A, Harrop C. Study of migraine and the treatment of acute attacks in industry. $J$ Int Med Res 1980;8:321-5. 